Universidad de Guadalajara

DERECHO GLOBAL. ESTUDIOS SOBRE DERECHO Y JUSTICIA Año 2021, Vol. VII. Número 19, Noviembre 2021-Febrero 2022, ISSN: 2448-5128 e-ISSN: 2448-5136

https://DOI.org/ 10.32870/dgedj.v6i19.401

VÍCTOR ALFONSO ROMÁN ACOSTA Universidad NaCional Experimental de los Llanos OcCidentales Ezequiel Zamora, Venezuela romanvictor2912@gmail.com

\title{
El Penitenciarismo Constitucional en Venezuela. Una Mirada Holística desde los Derechos Humanos
}

\section{The CONSTITUTIONAL PENITENTIARY RIGHTS}

Cómo citar el artículo:

Román V, (2021). El Penitenciarismo Constitucional en Venezuela. Una Mirada Holística desde los Derechos Humanos. Derecho Global, Estudios sobre Derecho y Justicia, VI (19) https://DOI. org/10.32870/dgedj.v6i19.401 pp. 113-141

Recibido: 05/09/2020 Aceptado: 02/03/2020 


\title{
RESUMEN
}

El propósito de este artículo es develar los principios, fundamentos y alcances del Sistema Penitenciario Venezolano, en el marco del Estado Democrático y Social de Derecho y de Justicia, sustentado en la vida, la libertad, la justicia, la igualdad y la preeminencia de los derechos humanos, como valores superiores. En ese sentido, el texto constitucional lega un modelo penitenciario humanista e inclusivo, que desluce de la realidad de la prisión venezolana actual. Esta producción se realizó en la matriz epistémica interpretativa, como una investigación documental de tipo monográfico, desarrollada a través de la matriz de análisis de contenido. Se utilizaron como técnicas la observación documental, la lectura evaluativa, las técnicas del resumen, del subrayado y de asociación, concluyendo en la necesidad de motorizar cambios desde la participación de los diversos actores sociales, como única vía para alcanzar la transformación penitenciaria, centrada en la dignidad del hombre.

\section{Palabras claves}

Prisiones, derechos humanos, constitución, estado de derecho.

\begin{abstract}
The purpose of this article is to reveal the principles, foundations and scope of the Venezuelan Penitentiary System, within the framework of the Democratic and Social State of Law and Justice, based on life, freedom, justice, equality and the pre-eminence of the human rights, as superior values. In this sense, the constitutional text bequeaths a humanistic and inclusive prison model, which is dim from the reality of the current Venezuelan prison. This production was carried out in the interpretive epistemic matrix, as a monographic documentary investigation, developed through the content analysis matrix. Documentary observation, evaluative reading, summary, underlining and association techniques were used as techniques, concluding inthe need to promote changes from the participation of the various social actors, as the only way to achieve prison transformation, focused on the dignity of man.
\end{abstract}

\section{KEY WORDS}

Prisons, human rights, constitution, rule of law. 
Sumario: I. Introducción. II. Metodología. III. Antecedentes del Sistema Penitenciario en Venezuela. IV. El Penitenciarismo en la Constitución de 1999. V. Realidad Carcelaria Actual. VI. Conclusiones. VII. Recomendaciones. Bibliografía.

Los cuatro verbos clásicos del penitenciarismo venezolano son: ociar, drogar, violar y matar.

Gómez Grillo (1989: 151)

\section{INTRODUCCIÓN}

La sociedad venezolana epocal es un reflejo de lo que no debe ser: ausencia de eticidad y moral; costumbrismo, aletargamiento y falta de apropiación de las herramientas legales, políticas y sociales para la solución de sus problemas; insensibilidad humana y desprecio por el otro; suficientes aristas para lograr una descomposición inimaginable a principios de siglo. Dentro de esta centrífuga de elementos, subyace la realidad de un grupo social vulnerable, los olvidados de siempre, marginados de ayer, invisibilizados hoy: las personas privadas de libertad. Ahí nuestra ocupación. Se trata de los colectivos que vive en contextos prisionales, con caracteres y valores comunes, así como metas, sueños, aspiraciones y objetivos.

Como se ha dicho, las personas privadas de libertad son individuos, sujetos de derecho, que transgredieron las leyes penales y en consecuencia, están sometidos a cumplir una condena, en un espacio aislado denominado cárcel, establecimiento penitenciario u organización penitenciaria ${ }^{1}$. La persona privada de libertad sufre

\footnotetext{
${ }^{1}$ El Código Orgánico Penitenciario define a los establecimientos penitenciarios en el artículo 3 ordinal 11 como: "Instalación con las adecuadas condiciones de infraestructura en la cual el órgano con competencia en materia penitenciaria presta la custodia, el seguimiento y atención integral a las personas privadas de libertad, en el mismo se garantizan el respeto de sus derechos y de los mecanismos necesarios para lograr su transformación". En un sentido cercano al humanismo, a juicio propio, son entidades integradas por por personas que viven una transición ecológica al abandonar su modo habitual de ser y estar en la sociedad, sus roles, por la integración a una comunidad con normas distintas, una subcultura (Bronfenbrenner, 1987; Melina y Mikulic, 2004) sometidos a una privación física, pero con un objetivo común: la libertad; y en consecuencia, la inevitable preparación para la reinserción social.
} 
un cambio de hábitat, del mundo social en libertad a una frontera a la que es limitada su libertad de movimiento, donde poco puede decidir por sí mismo, mientras cumple su condena, sometido a las normas del régimen penitenciario ${ }^{2}$. Ensimilar sentido, la privación de libertad es una transición que padece la persona, en la búsqueda nuevamente de su libertad, que comporta un proceso de transformación, conjugado con el ejercicio de sus derechos como persona y el cumplimiento de actividades guiadas, en el marco del nuevo paradigma de los derechos humanos ${ }^{3}$.

Dicho de esta manera, las personas privadas de libertad son acreedoras de derechos, pero también tienen obligaciones y deberes que cumplir, para transitar hacia la integración social. Por lo tanto, la "rehabilitación" o "reeducación", más que volver a habilitar o desestructurar lo aprendido y estructurar nuevos saberes, es la construcción de vivencias, prácticas y empoderamiento de valores a través del trabajo, la educación, el deporte, la recreación, la cultura y la instrucción disciplinaria para la emancipación; configurando principios nucleares que validan el paso a la reinserción social.

Por consiguiente, las organizaciones penitenciarias son entes para la transformación individual y social de las personas privadas de libertad, proyectadas a la

\footnotetext{
${ }^{2}$ El Régimen Penitenciario, conforme al artículo 3 numeral 23 del Código Orgánico Penitenciario (2015) son las "Normas y procedimientos que rigen la convivencia, el buen orden y las actividades propias de las personas privadas de libertad".

${ }^{3}$ Un nuevo paradigma surge en medio de una crisis de la ciencia, para dar una respuesta clara a un fenómeno determinado. En este caso, el paradigma etiológico, construido desde la criminología como postura científica para el análisis y observación de las personas sometidas a la cárcel, y la aplicación del "tratamiento" para su rehabilitación. Por lo tanto, el paradigma de los Derechos Humanos, germina sobre los pies de la Declaración Universal de los Derechos del Hombre, la Carta de las Naciones Unidas, la Convención Americana de los Derechos Humanos y las Reglas Mínimas de las Naciones Unidas para los reclusos, centrado en la dignidad humana, considerando a la persona penitenciaria como un sujeto de derechos, dejando atrás los necesarios tratamiento para la reinserción, por el acompañamiento de los privados de libertad en un proceso de transformación conductual que se ejerce en el marco del goce de sus derechos fundamentales, además del cumplimiento de actividades humanistas como el trabajo, la educación, el deporte, la recreación, la cultura, las artes, la disciplina y el orden, sin que se confundan el ejercicio de derechos frente al cumplimiento de mecanismos para la integración.
}

\section{DERECHO GLOBAL. ESTUDIOS SOBRE DERECHO Y JUSTICIA}


resocialización. Más allá de las fronteras y barrotes, representan un cúmulo de aspiraciones, metas, sueños y esperanzas de sus miembros. Dicho a través de otro ejemplo, al amparo del paradigma de los derechos humanos ${ }^{4}$, se desmitifica la concepción de la cárcel como un espacio físico, depósito o almacén humano.

De este modo, el penitenciarismo constitucional moderno es una nueva forma de ver y pensar la cárcel ${ }^{5}$, no como el instituto tota ${ }^{6}$ de otrora, sino como una armonización de elementos materiales y espirituales, en las que sus actores protagonizan el proceso transformacional, redimiendo sus penas, como hombres nuevos. Esta investigación tiene como propósito general analizar el sistema penitenciario venezolano a la luz del texto constitucional venezolano desde la perspectiva de los derechos humanos, para lo cual se plantea los siguientes propósitos específicos: 1) develar los antecedentes y fundamentos del penitenciarismo constitucional venezolano; 2) describir la realidad penitenciaria actual; 3) interpretar el sistema penitenciario desde la esfera de los derechos humanos.

\footnotetext{
${ }^{4}$ El paradigma constitucional de los Derechos Humanos está sustentado por una serie de elementos propios de la naturaleza del Hombre. Según Pizano (2013: 54) algunos pueden ser “... vida, libertad, no discriminación, integridad personal, trabajo, educación, salud, capacitación, dignidad y respeto. Este primer tema hace referencia a los elementos que comprenden la argumentación originaria de las cualidades y calidades de los individuos, a partir de los derechos humanos y la readaptación social. Esta última establecida en doble vertiente: a) reeducación de la conciencia social del interno; b) reinserción social de la persona"

${ }^{5}$ El Penitenciarismo Constitucional descansa en el paradigma de los derechos humanos, que efectivamente es un forma de visualizar la realidad, transversalizada en la dignidad del hombre, pues, según Lugo (2018: 84) "el investigador, al aproximarse a determinada realidad, asume una perspectiva epistemológica que le permite dilucidar cómo va obtener conocimiento de la misma, el estatus que se le debe asignar a las interpretaciones y comprensiones que se alcanzan, todo lo cual dependerá de cómo observa esa realidad y de su propia interacción con ella". Por tanto, el nuevo penitenciarismo debe ser abordado tanto a nivel de estudio, investigación y acción gerencial desde la perspectiva de los derechos humanos, entendiendo que los derechos son exigibles, y que las personas privadas de libertad son sujetos de derecho y el Estado debe garantizarlo, en corresponsabilidad con la familia, la sociedad, las empresas y el resto de los actores sociales.

${ }^{6}$ Según Goffman (2001: 13) "Una institución total puede definirse como un lugar de residencia o trabajo, donde un gran número de individuos en igual situación, aislados de la sociedad por un período apreciable de tiempo, comparten en su encierro una rutina diaria, administrada formalmente. Las cárceles sirven como ejemplo notorio...".
} 


\section{Metodología}

Este artículo se desarrolló en el paradigma interpretativo (Leal, 2017: 127), que busca interpretar y comprender al individuo para fijar su propio sentido. La naturaleza del estudio es documental, de tipo monográfico. Como consecuencia de ello, se realizó una recolección de datos en forma sistemática, ordenada, secuencial, acudiendo a fuentes fidedignas sobre el penitenciarismo constitucional venezolano, sus antecedentes, fundamentos y realidad actual, a través de la observación documental, la lectura evaluativa, las técnicas del resumen, del subrayado y de asociación, formando un repositorio, acentuando en los aspectos críticos para extraer las aproximaciones teóricas que consoliden el tejido neurálgico de la investigación, a través de la matriz de análisis del contenido categorizado (Bardin, 2002: 32), complementado a través del método analítico, lógico y crítico. La investigación es simétrica con el paradigma de los derechos humanos como superación del paradigma etiológico o de la rehabilitación, a pesar que el texto constitucional venezolano ubicó el término "rehabilitación" en la norma matriz (artículo 272) ${ }^{7}$.

\footnotetext{
${ }^{7}$ Creemos fielmente que el Constituyente fue ambivalente al mencionar "rehabilitación" y el "respeto a los derechos humanos" en la norma que regula el sistema penitenciario venezolano. Haber dado un paso al frente en el paradigma de los derechos humanos, en el siglo XX y XXI, era caracterizada por el resguardo internacional de la dignidad humana, y mantener el término "rehabilitación", pareciera dubitativo y anclar al pasado al modelo penitenciario. De hecho, Morais (2010: 11) expresa que: "Venezuela sigue anclada en las concepciones penal-criminológicas del siglo XIX, según las cuales el delincuente es un ser anormal, enfermo, diferente de los demás hombres. Por lob tanto, durante la privación de libertad se debería someterlo a un "tratamiento" para "curarlo" y "resocializarlo", es decir, rehabilitarlo para después reinsertarlo en la sociedad, una vez que acepte y adopte las reglas de conducta que impone la convivencia social. Para lograr el cambio se ha considerado como estrategias terapéuticas lo que en realidad son derechos de los reclusos: asistencia médica, religiosa y social, el trabajo, el estudio y la recreación. Ocurre que las estrategias terapéuticas no son exigibles, pero los derechos sí". Pese a ello, consideramos que el texto constitucional, al dotar de eficacia directa a sus normas y principios, en una interpretación axiológica de dicha norma, debe enfatizar y acobijar al sistema penitenciario en el paradigma de los derechos humanos, superando los escollos de la rehabilitación, más bien por una transformación del individuo, que solo podrá desarrollar a través de cambios en su conciencia social y de la mano de la oportunidad de los diferentes actores sociales. No somos partidarios, teóricamente, de que el término "rehabilitación" signifique una barrera para la humanización del sistema penitenciario, empero, la problemática real de los penales devela que no hay rastros ni de la rehabilitación ni del goce de los derechos humanos.
}

\section{DERECHO GLOBAL. ESTUDIOS SOBRE DERECHO Y JUSTICIA}




\section{Antecedentes del Sistema Penitenciario en VENEZUELA}

La atrocidad y crueldad en contra de las personas privadas de libertad ha sido un signo característico del sistema penitenciario venezolano desde sus orígenes, a pesar de que en el devenir de la historia las leyes regulatorias de la materia se inclinen hacia el impulso de actividades que desvanezcan el ocio, los tratos crueles o humillantes, las violaciones y muertes. Es así que, en la época colonial, se aplicaron sanciones aflictivas distando abismalmente a cualquier alternativa educativa para los prisioneros. La sanción corporal ascendía a diez años como pena máxima y también se aplicó la pena de muerte, los azotes, las torturas y la mutilación (Gómez Grillo, 2000: 173).

La primera Ley de Régimen Penitenciario se aprueba en Venezuela en 1915 y posteriormente se decretan otros instrumentos legales semejantes en 1916, 1926, 1937 y 1961, reformada en 1981 (Gómez Grillo, 2000). Al final de la dictadura Gomecista, en 1936, empieza una nueva era para nuestro país y también para el Penitenciarismo, enmarcado en la contemporaneidad y los idearios de Tulio Chiossone, patentados en la obra "Organización Penitenciaria Venezolana" (1936), a quien se le considera por sus aportes fecundos como Padre del Penitenciarismo en Venezuela. La Ley de Régimen Penitenciario de 1961 se redactó inspirada en las Reglas Mínimas de las Naciones Unidas para el Tratamiento de los Reclusos, destacando entre sus logros "el sistema progresivo -concesión de beneficios al recluso de acuerdo a su conducta-" (Gómez Grillo, 2000: 176). Empero, el auge delictivo nacional incrementó el número de la población penal, desbordando los centros penitenciarios de la época, aunado al retraso procesal de los Tribunales Penales, hecho aún vigente, lo que convirtió a las cárceles venezolanas y con ello, a su sistema, en depósitos de hombres.

Posterior a ello, en 1981 al reformar la Ley del Régimen Penitenciario, se le adecua a los mandamientos de la moderna penología (Morais, 1992: 104), alcanzando logros significativos, como bien describe Gómez Grillo (2000: 178): 
Además, en el aspecto penológico general, fue el gobierno que hizo realidad el logro progresista quizás más importante de toda nuestra historia sancionatoria, como lo es la puesta en vigencia de la Ley de Sometimiento a Juicio y Suspensión Condicional de la Pena, sancionada el $1^{\circ}$ de abril de 1980, con la que Venezuela se coloca a la vanguardia de la modernidad legislativa penal del mundo hispanoparlante, ya que se trata del establecimiento del régimen probatorio. Se aprobó, además, la Ley de Registro de Antecedentes Penales, dirigida hacia una finalidad loable de buena política criminal. Se pusieron en funcionamiento las primeras cárceles abiertas o Centros de Tratamiento Comunitario que conoció el país y se reformó la Ley de Régimen Penitenciario, con algunas mejoras en cuanto a la regulación de determinados beneficios. Ese gobierno instituyó, además, los muy exitosos Festivales de Teatro Penitenciario y aprobó la Ley Tutelar del Menor.

En 1990 es creado mediante Decreto Presidencial No 1.313 el Instituto Universitario Nacional de Estudios Penitenciarios (IUNEP), el cual se inauguró el 3 de febrero de 1992 (Gómez Grillo, 2009: 48), con la finalidad de profesionalizar al personal penitenciario mediante la formación de Técnicos Superiores Universitarios en Penitenciarismo, con especialidad en cuatro menciones; a saber: Administración Penitenciaria, Educación Penitenciaria, Gerencia Penitenciaria y Seguridad Penitenciaria.

En esta orbita, una profundización penitenciaria centrada en el paradigma de los derechos humanos inicia en 1999, con la entrada en vigencia del Código Orgánico Procesal Penal, que enarbola los principios de la presunción de inocencia (artículo 8), afirmación de la libertad (artículo 9) y respeto a la dignidad humana (artículo 10) así como la obligación de los jueces de ejecución de visitar los establecimientos penitenciarios (artículo 471) ${ }^{8}$.

En el año 2000, se dicta una nueva la Ley del Régimen Penitenciario que, según Áñez (2015: 23) "ratifica en su artículo 2, el mandato constitucional que afirma

\footnotetext{
${ }^{8}$ El Juez de Ejecución está encargado de velar por el cumplimiento de las penas y medidas de seguridad impuestas mediante sentencia firme. Por otro lado, antes de la entrada en vigencia del Sistema Penal Acusatorio, bajo la regulación del Código de Enjuiciamiento Criminal, se establecía la obligación de los funcionarios judiciales de realizar visitas periódicas a los establecimientos penitenciarios, dejando constancia del adecuado funcionamiento de los mismos. Creemos que, a rezar por la historia, no se cumplió.
} 
como objetivo fundamental de la pena, la reinserción social del penado, en estricto respeto a todos los derechos inherentes a la persona humana". Luego, en el año 2011 se crea el Ministerio del Poder Popular para el Servicio Penitenciario (conforme a la Gaceta Oficial No 39.721, con fecha 26 de julio de 2011, vía decreto $\mathrm{N}^{\circ}$ 8.266). Posteriormente, en el año 2013, es aprobado el Código Orgánico Penitenciario, publicado en Gaceta Oficial en 2015, como norma regulatoria y compilatoria de toda la materia penitenciaria, vigente, hasta el momento.

\section{El Penitenciarismo en la Constitución de 1999}

\section{La Constitución (primera en entrar al tema penitenciario) ${ }^{9}$ concibió un modelo} humanista y social posible, no utópico, entendiendo los fines sociales de la pena y la igualdad de derechos de las personas privadas ${ }^{10}$. Desde la aprobación del texto constitucional, Venezuela como Estado Social de Derecho y de Justicia ${ }^{11}$, asume

\footnotetext{
${ }^{9}$ Gómez Grillo (2001: 99) manifiesta que: "la nueva constitución Venezolana es la primera que en la historia penetra en la cárcel al garantizar la rehabilitación del interno y el respeto a sus derechos humanos".

${ }^{10}$ Morais (2010: 2) señala que: "Todos los privados de libertad, sin excepción, tienen derechos. El procesado, vista la presunción de inocencia de la cual goza, el único derecho que tiene restringido es el de la libertad de tránsito...” y sumado a ello (ob. cit.: 3 ) indica que: “...El sujeto penalmente condenado también tiene derechos: los fundamentales, inherentes a toda persona humana, reconocidos en Convenios y Pactos Internacionales, consagrados en las Constituciones a favor de todas las personas y que no se pierden por efectos de la condena penal, así como los específicos que se derivan de la sentencia condenatoria, de la particular relación que se establece entre el sancionado y el Estado que lo condenó".

${ }^{11}$ El artículo 2 de la Constitución expone que: "Venezuela se constituye en un Estado democrático y social de Derecho y de Justicia, que propugna como valores superiores de su ordenamiento jurídico y de su actuación, la vida, la libertad, la justicia, la igualdad, la solidaridad, la democracia, la responsabilidad social y en general, la preeminencia de los derechos humanos, la ética y el pluralismo político"; Useche (2001: 8) explica que: "El Estado de Derecho implica la sumisión del Estado y de los individuos y organizaciones sociales al ordenamiento jurídico, respecto del cual la Constitución define como sus valores superiores, al igual que de la actuación del Estado: la vida, la libertad, la justicia, la igualdad, la solidaridad, la democracia, la responsabilidad social, la ética y el pluralismo político, estos valores deben informar el ordenamiento jurídico y guiar la actuación del Estado. El Estado de Derecho encierra un orden axiológico; es ante todo un garante de las libertades públicas y la seguridad jurídica. El Estado de Derecho no ha perdido con el transcurrir del tiempo su vertiente valorativa, sino al contrario se ha convertido en un núcleo. El Estado de Derecho se legitima en tanto y en cuanto se asienta en un conjunto de valores, en un orden valorativo al que debe responder y que ha de impregnar a todo el ordenamiento jurídico".
} 
un carácter humanista del sistema penitenciario, como se observa en el artículo 272 que consagra:

El Estado garantizará un sistema penitenciario que asegure la rehabilitación del interno o interna y el respeto a sus derechos humanos. Para ello, los establecimientos penitenciarios contarán con espacios para el trabajo, el estudio, el deporte y la recreación, funcionarán bajo la dirección de penitenciaristas profesionales con credenciales académicas universitarias, y se regirán por una administración descentralizada, a cargo de los gobiernos estadales o municipales, pudiendo ser sometidos a modalidades de privatización. En general, deberá preferirse en ellos el régimen abierto y el carácter de colonias agrícolas penitenciarias. En todo caso las fórmulas de cumplimiento de penas no privativas de la libertad se aplicarán con preferencia a las medidas de naturaleza reclusoria. El Estado creará las instituciones indispensables para la asistencia postpenitenciaria que posibilite la reinserción social del exinterno o exinterna y propiciará la creación de un ente penitenciario con carácter autónomo y con personal exclusivamente técnico.

Derivado de esta norma rectora, Gómez Grillo (2001: 99) visiona siete principios esenciales ${ }^{12}$ para la acción en el campo penitenciario. Dichos pilares serán descritos aquí en nueve aspectos teóricos: primero) "Institucionalización de las Personas sometidas al Sistema Penitenciario", que se sustenta en dos bastiones: a) la rehabilitación del interno o interna y b) el respeto a sus derechos humanos, en búsqueda de la reinserción social, que depende de las siguientes condiciones previas (intra-muros):

1. La adherencia institucional del individuo a la organización penitenciaria.

2. la no asimilación de las normas de la subcultura delincuencial.

3. Apoyo socio familiar constante durante la privación de libertad.

4. Promoción de la educación como eje impulsor de la libertad pensamiento y expresión.

5. Facilitar los medios laborales, deportivos, artísticos y recreativos.

6. Participación en actividades comunitarias.

\footnotetext{
${ }^{12}$ Esos principios esenciales son: profesionalización, descentralización, régimen abierto y colonias agrícolas, medidas no privativas de libertad, asistencia postpenitenciaria, independencia técnica y privatización.
}

\section{DERECHO GLOBAL. ESTUDIOS SOBRE DERECHO Y JUSTICIA}


7. Fortalecimiento de la libertad de religión y de cultos.

8. Prohibición del uso de drogas y alcohol.

9. Disminución de la violencia mediante el uso de los mecanismos alternativos para la resolución de conflictos.

10. Tolerancia al resto de las personas con las que convive forzadamente.

De igual forma, el respeto a los derechos humanos consiste en la posibilidad de las personas privadas de libertad de exigir condiciones mínimas para su proceso de transición, adecuando el servicio penitenciario a las normas internacionales, constitucionales y legales centradas en la dignidad del hombre, tal como prescribe la Regla 1 de las Naciones Unidas para el Tratamiento de los Reclusos o Reglas Mandela (2015) que contiene: "Todos los reclusos serán tratados con el respeto que merecen su dignidad y valor intrínsecos en cuanto seres humanos”. Sobre esta base, Román (2020a: 66) ${ }^{13}$ ha expresado que:

El Ministerio del Poder Popular para los Servicios Penitenciarios, las autoridades penitenciarias locales, funcionarios de custodia, familiares, amigos, consejos comunales, deben promover el respeto de los derechos humanos. De hecho, son pocos los compromisos de la sociedad con las personas privadas de libertad; regularmente son etiquetados al salir de la cárcel, se le cercenan oportunidades laborales y de estudio. Para evitar esto, hay que empoderar a todas los privados de libertad de estrategias comunicacionales sobre sus derechos y obligaciones.

\section{El segundo sustento secuencial es "La Organización Penitenciaria como}

Entidad Funcional", ceñido a la norma que define: "...los establecimientos penitenciarios contarán con espacios para el trabajo, el estudio, el deporte y la recreación”, por lo tanto, la cárcel ya no es un conglomerado humano sin normas,

\footnotetext{
${ }^{13}$ En este artículo se hace una descripción de diferentes insumos gerenciales que permiten disminuir los efectos de la prisionización o encarcelamiento, desde el eje central de los derechos humanos. Véase: Román, V. (2020a). Insumos gerenciales emergentes para la disminución de los efectos de la prisionización. Revista Científica Gerens (6), enero-junio 2020. pp. 61-70. Disponible en: http://www.unellez.edu.ve/revistas/index. php/rgerens/article/download/1091/983
} 
sino un ente promotor del desarrollo de las personas a través de las actividades redentoras.

Luego, el tercer sustento es "Gerencia y Asistencia Penitenciaria Profesional - Multidisciplinar", que responde al principio de la profesionalización (Gomez Grillo, ob. cit.) el cual compele a la dirección de las organizaciones en manos de “(...) penitenciaristas profesionales con credenciales académicas universitarias”; despolitizando el manejo de los centros de reclusión y fomentando la labor de verdaderos penitenciaristas ${ }^{14}$.

\section{El cuarto aspecto es la "Forma de Organización Administrativa Penitenciaria",} bajo la galera de los principios de la descentralización y privatización, por lo que las competencias del servicio penitenciario deben ser transferidas a los estados y municipios. Un quinto sustento teórico-normativo se extrapola como "Modalidades de Funcionamiento de las Organizaciones Penitenciarias", bajo la preferencia del “(...) régimen abierto y el carácter de colonias agrícolas penitenciarias".

El sexto engranaje corresponde con "El Uso de la Privación de Libertad en casos estrictamente necesarios", lo que concuerda con el principio universal de la presunción de inocencia. Correlacionado a ello, el séptimo eslabón es la "Asistencia Postpenitenciaria" para garantizar la resocialización, lo que implica:

1. Voluntad irrestricta e inequívoca de no volver a delinquir, no reincidir.

2. El apoyo de la familia (moral, económico).

3. La interacción con nuevos círculos de amigos.

4. El apoyo de la sociedad.

\footnotetext{
${ }^{14}$ El Estado Venezuela cuenta ahora con la Universidad Nacional Experimental de la Seguridad (UNES) para la formación de profesionales en esta área. Creemos que, más allá de la capacitación de los mismos, debe generarse una verdadera inversión en las condiciones laborales y salariales, para garantizar un efectivo cumplimiento de sus funciones.
} 
5. El cumplimiento del sistema jurídico vigente.

6. El acompañamiento del Estado a través de políticas públicas que favorezcan la ocupación, renta o adquisición de viviendas, igualdad en el mercado laboral mediante la proscripción deluso del antecedente penal como forma de discriminación social y jurídica, tal como estipula el artículo 166 del Código Orgánico Penitenciario ${ }^{15}$.

7. Políticas empresariales de segunda oportunidad.

8. La confidencialidad del Registro de Antecedentes Penales de las personas condenadas por un delito por parte de los organismos autorizados por el Estado (conforme al artículo 28 de la Constitución de la República Bolivariana de Venezuela). ${ }^{16}$

9. La corresponsabilidad Estado- Familia- Universidad- Empresa- SociedadEgresado para rehacer su vida en la armonía social.

Como otro aspecto teórico podemos destacar la creación de las UTSO Unidades Técnicas de Supervisión y Orientación ${ }^{17}$, como ente penitenciario con carácter autónomo y con personal exclusivamente técnico, el cual tendrá como misión el seguimiento y acompañamiento de los sujetos penitenciarios. Respecto al funcionamiento de este ente, Payares y Boueri (2011) han asegurado que:

\footnotetext{
${ }^{15}$ El artículo 166 establece textualmente "El penado o penada que haya cumplido su pena y el que de algún otro modo haya extinguido su responsabilidad penal debe gozar de inmediato del ejercicio pleno de todos sus derechos como ciudadano o ciudadana. En ningún caso los antecedentes penales podrán ser motivo de discriminación social o jurídica, a tal efecto las unidades de apoyo postpenitenciario del Ministerio del Poder Popular con competencia en materia penitenciaria velarán por que el uso de la información relacionada con dichos antecedentes penales no afecte ilegítimamente los derechos de los ex internos o ex internas".

${ }^{16}$ La norma del artículo 28 de la Constitución corresponde con el recurso de habeas data al prescribir: "Toda persona tiene derecho de acceder a la información y a los datos que sobre sí misma o sobre sus bienes consten en registros oficiales o privados, con las excepciones que establezca la ley, así como de conocer el uso que se haga de los mismos y su finalidad, y a solicitar ante el tribunal competente la actualización, la rectificación o la destrucción de aquellos, si fuesen erróneos o afectasen ilegítimamente sus derechos..."

${ }^{17}$ De acuerdo al artículo 168 del Código Orgánico Penitenciario “...Las unidades técnicas de supervisión y orientación, prestarán el servicio de orientación y supervisión a aquellos procesados, procesadas, penados y penadas a quienes se les haya otorgado una medida de suspensión condicional del proceso, medidas cautelares, suspensión condicional de la ejecución de la pena y libertad condicional...".
} 
(...) las dificultades en el funcionamiento actual de la institución están más asociadas a la poca claridad en los objetivos que se persiguen y en los medios para lograrlo, que en los problemas técnico-operativos señalados por el personal durante las entrevistas.

\section{Un noveno aspecto a considerar es: "La Interrelación Cárcel-Comunidad-} Cárcel", rompiendo las fronteras entre la prisión y la sociedad, como prevé el artículo 184 ordinal séptimo de la Constitución que contempla:

La ley creará mecanismos abiertos y flexibles para que los Estados y los Municipios descentralicen y transfieran a las comunidades y grupos vecinales organizados los servicios que éstos gestionen previa demostración de su capacidad para prestarlos, promoviendo: 7. La participación de las comunidades en actividades de acercamiento a los establecimientos penales y de vinculación de éstos con la población.

La participación de las comunidades en las cárceles es una gestión avanzada en el penitenciarismo mundial. Al respecto, Gómez Grillo (2000, p. 188) enuncia que:

Esto quiere decir que la población libre entrará a las cárceles para participar con la población reclusa en actividades comunitarias -folklóricas, culturales, pedagógicas, artísticas, deportivas, laborales-, y la población reclusa saldrá a la calle para unirse a la población libre participando en manifestaciones de su vida colectiva. Esto es lo que se está haciendo desde hace mucho tiempo, en los países de mejor penitenciarismo del mundo: la desaparición de las fronteras entre la cárcel y la comunidad. La cárcel incorporada a la comunidad y la comunidad incorporada a la cárcel.

\section{A continuación, se presenta el Mapa Conceptual Número. 1 "Sustentos Teóricos del Penitenciarismo Constitucional Venezolano". ${ }^{18}$}

\footnotetext{
${ }^{18}$ A efectos de estudio, se ofrece el Mapa Conceptual Nro. 1 "Sustentos Teóricos del Penitenciarismo Constitucional Venezolano", en el que se grafican los nueve elementos aludidos, soportados en los principios esenciales del penitenciario, para garantizar la transformación de las personas penitenciarias en el marco del Estado Democrático y Social de Derecho y de Justicia.
} 




Fuente: Elaboración Propia

\section{Realidad Carcelaria Actual}

El Estado Venezolano se encuentra en mora en la prestación de un servicio penitenciario eficiente, eficaz y efectivo, vulnerando los postulados constitucionales vigentes. En refuerzo de ello, Morais (2009: 2) enuncia que:

No cabe duda de que el marco jurídico venezolano, pese a algunas deficiencias, incoherencias e inconsistencias, tanto en la norma constitucional como en las legales, es suficiente para propiciar la garantía de los derechos humanos de los reclusos. Pero una cosa es el reconocimiento formal de unos postulados garantizadores de derechos humanos y otra muy distinta es la verificación efectiva de los mismos en el interior de las instituciones penales. La historia y la realidad de las prisiones ponen de manifiesto que es precisamente alli donde se vulneran todos y cada uno de los derechos de los reclusos. 
En una mirada a las realidades de las prisiones venezolanas, en primer orden, "la rehabilitación del interno o interna", no es medible ni verificable en Venezuela, ya que no se efectúan estudios que validen el proceso "rehabilitador". El Ministerio del Poder Popular para el Servicio Penitenciario ha centrado sus esfuerzos en deshacinar, lo cual no ha sido logrado, ante la desbordante criminalidad y la inoperatividad de los tribunales de justicia, caracterizado por excesivos volúmenes de causas y retardo procesal injustificado.

En segunda instancia, en el espectro de los derechos humanos, los comentarios huelgan por sí solos, configurando una violación sistemática durante los últimos 50 años (Morais, ob. cit.: 2). Las múltiples vulneraciones a los derechos fundamentales han sido denunciadas por las diferentes organizaciones no gubernamentales, como el Programa Venezolano de Educación-Acción ${ }^{19}$ y el Observatorio Venezolano de Prisiones ${ }^{20}$, frente a los incomensurables esfuerzos del Ministerio por mantener la paz en las organizaciones penitenciarias. Entre las transgresiones a los derechos humanos destacan: a) hacinamiento ${ }^{21}$; b) densidad poblacional crítica $^{22}$; c) ausencia de clasificación de las personas privadas de

${ }^{19}$ El Programa Venezolano de Educación Acción en Derechos Humanos (Provea) fue creado en Caracas el 15 de octubre de 1988 como una organización no gubernamental con énfasis en los llamados Derechos Económicos, Sociales y Culturales (DESC), sin dejar de lado la interdependencia e integralidad del conjunto de derechos humanos... Provea educa y apoya jurídicamente a sectores vulnerables víctimas o potenciales víctimas de violaciones de derechos humanos; documenta e investiga sobre su situación y denuncia los abusos de poder y violadores de derechos humanos, articulando con otras organizaciones y movimientos sociales y populares. (Fuente: PROVEA, nuestra historia. En: https://www.derechos.org.ve/provea).

${ }^{20}$ El Observatorio Venezolano de Prisiones es una ONG fundada en el año 2002 con la misión de velar porque se respeten los Derechos Humanos de la población privada de libertad a nivel nacional (OVP, 2015, p. 2)

${ }^{21}$ El Hacinamiento en las cárceles venezolanas representa un $170 \%$ de acuerdo a las cifras publicadas por la Organización No Gubernamental "Observatorio Venezolano de Prisiones", para el año 2015, correspondiendo los números a Diciembre de 2014, en donde se transcribe que “... hay 51.256 personas, de las cuales: 31.860 son procesados, 18.316 son penados, 590 están bajo Destacamento de trabajo y 490 se encuentran en depósitos policiales. De acuerdo a la distribución por sexo, existen 48.314 hombres (94\%) y 2.942 mujeres (6\%) en cincuenta y un centros penitenciarios a nivel nacional. La capacidad instalada total es de 19.000 plazas, por lo que el hacinamiento alcanza el porcentaje de 170" (Ob. cit., p. 3). A tal efecto, véase el Gráfico Nro. 1 "Hacinamiento en Venezuela para el 2015".

${ }^{22}$ La Densidad poblacional crítica se explica por la diferencia numérica entre el número de cupos para insertarse en los programas educativos y laborales frente al número de personas privadas de libertad. 
libertad ${ }^{23}$; d) poquedad de funcionarios de seguridad y custodia para garantizar la tranquilidad de los centros de reclusión ${ }^{24}$; e) infraestructura deplorable ${ }^{25}$; f) ofertas laborales escasas sin contribución a la acervo económico del trabajador; g) ofertas educativas exiguas; $h$ ) ausencia de condiciones para mantener una vida sexual digna; i) falta de material deportivo para la realización de actividades de esta índole; j) tratos crueles, inhumanos y degradantes en las instituciones penitenciarias $^{26}$; k) escasez hídrica; 1) falta de alimentación balanceada; m) maltrato por parte de las autoridades penitenciarias tanto a los privados de libertad como a los visitantes; $n$ ) coexistencia de centros penitenciarios bajo el liderazgo de reclusos denominados PRANES, lo que se traduce como una forma de violencia ejercida por los internos entre sí mismos ${ }^{27}$; o) aislamiento de personas

${ }^{23}$ En vulneración a las Reglas Mandela, no hay una clasificación de las personas privadas de libertad ni por condiciones (procesadas o penadas), ni por delitos, ni pro edad o condición de salud.

${ }^{24}$ En un establecimiento penitenciario para trescientas personas como el Centro Penitenciario de Carabobo "Mínima de Tocuyito" en el estado Carabobo hubo ochocientas sesenta y siete personas para la fecha del 27 de abril de 2020, una sobre saturación de los dormitorios y espacios de vida diaria, pero además de ello, tan solo hubo treinta funcionarios de seguridad y custodia para garantizar la tranquilidad y seguridad.

${ }^{25}$ Véase a tales efectos la Ilustración Nro. 1 "Imagen del Internado Judicial de Tocuyito, Valencia, estado Carabobo".

${ }^{26}$ Sobre los tratos crueles han sido denunciados por parte de familiares y visitantes la violencia institucional desde que los mismos llegan a ejercer su derecho a la visita: a) largas horas de espera para acceder a la sala de visita; b) matraqueo (término vulgar para aludir a la extorsión por parte de funcionarios), para pasar antes o dejar pasar algunas cosas prohibidas; c) violación a la intimidad en las revisiones de las mujeres y hombres. Asimismo, en lo interno de las cárceles, los funcionarios enseñan, corrigen y castigan con los siguientes medios: en la forma más dulce mediante la imposición de flexiones, abdominales y ejercicios premilitares. Eso aumenta los niveles a: llevar sol o agua; "mata chivos" o golpes en la nuca, planazos, tablazos, peinillazos, corriente eléctrica mediante instrumentos denominados "garrochas"; esposar a los castigados en una cerca o tela metálica para que los demás los vea, normalmente "guindados", aislamiento en "tigritos" o espacios ultra reducidos, sin acceso a la luz, quizás de 1 metro cuadrado, normalmente hacinados también. La violencia sigue su escalada con los traslados a otros penales alejados de la zona donde sus familiares viven, en donde pasarán a ser "pobres diablos", abandonados.

${ }^{27}$ En el Penal de Tocuyito o Tocorón el poder está en manos de los pranes, quienes son otros internos, en situación de poder por las armas de fuego que poseen y manejo de la droga. Ellos cobran la llamada "causa", una cantidad de dinero semanal que deben suministrar cada uno de los internos para poder vivir, de lo contrario son castigados y echados al "aniegue", un área donde reposan los cuerpos de quienes no pagaron la causa o violaron las reglas del "sistema" (anterior rutina). Ese aniegue puede ser la placa o techo de uno de los edificios que forme la cárcel, en donde no accederán ni a los alimentos, ni servicios sanitarios, hasta que las autoridades los trasladen a un penal a cargo del Ministerio. 
privadas de libertad como formas de reflexión y castigo; p) inaccesibilidad de las comunidades para la interrelación con las personas privadas de libertad en vulneración de lo preceptuado en el texto constitucional; q) ausencia de equipos multidisciplinarios para el tratamiento de los internos; r) falta de personal médico, enfermeros, y recursos de salud; s) existencia de presos por razones políticas y mezclados con la población común, entre otros muchos aspectos ${ }^{28}$.

A continuación, se presentan tres gráficos en los que se muestra el hacinamiento de la población penal total en Venezuela, por condición de procesados o penados y por sexo.

\section{Gráfico Nro. 1 "Hacinamiento en Venezuela para el 2015"}

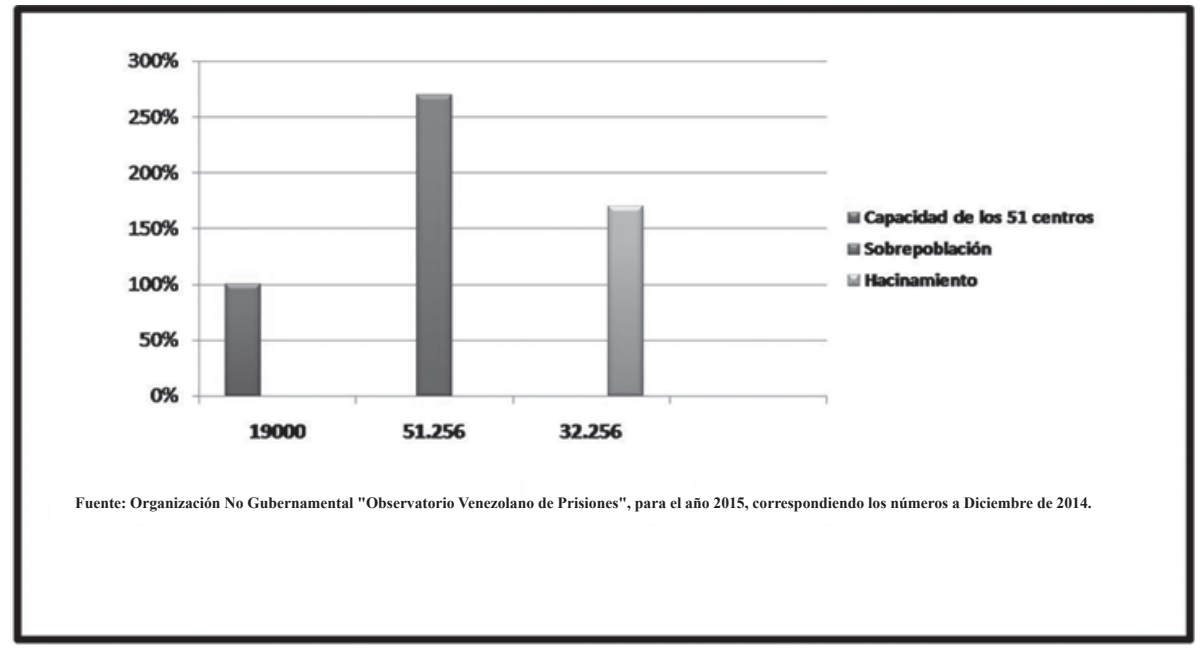

Fuente: Elaboración propia.

\footnotetext{
${ }^{28}$ La Organización No Gubernamental "Foro Penal" denuncia “... que el país ha entrado en el año 2020 con la cifra récord de 388 presos políticos, de los cuales 370 son hombres y 18 mujeres...". Véase: Notimerica, "Venezuela inicia el año 2020 con la cifra récord de 388 presos políticos, según Foro Penal”. En: https://www. notimerica.com/politica/noticia-venezuela-venezuela-inicia-ano-2020-cifra-record-388-presos-politicos-foropenal-20200103222350.html
}

\section{DERECHO GLOBAL. ESTUDIOS SOBRE DERECHO Y JUSTICIA}


Gráfico Nro. 2 "Discriminación de la población por condición”

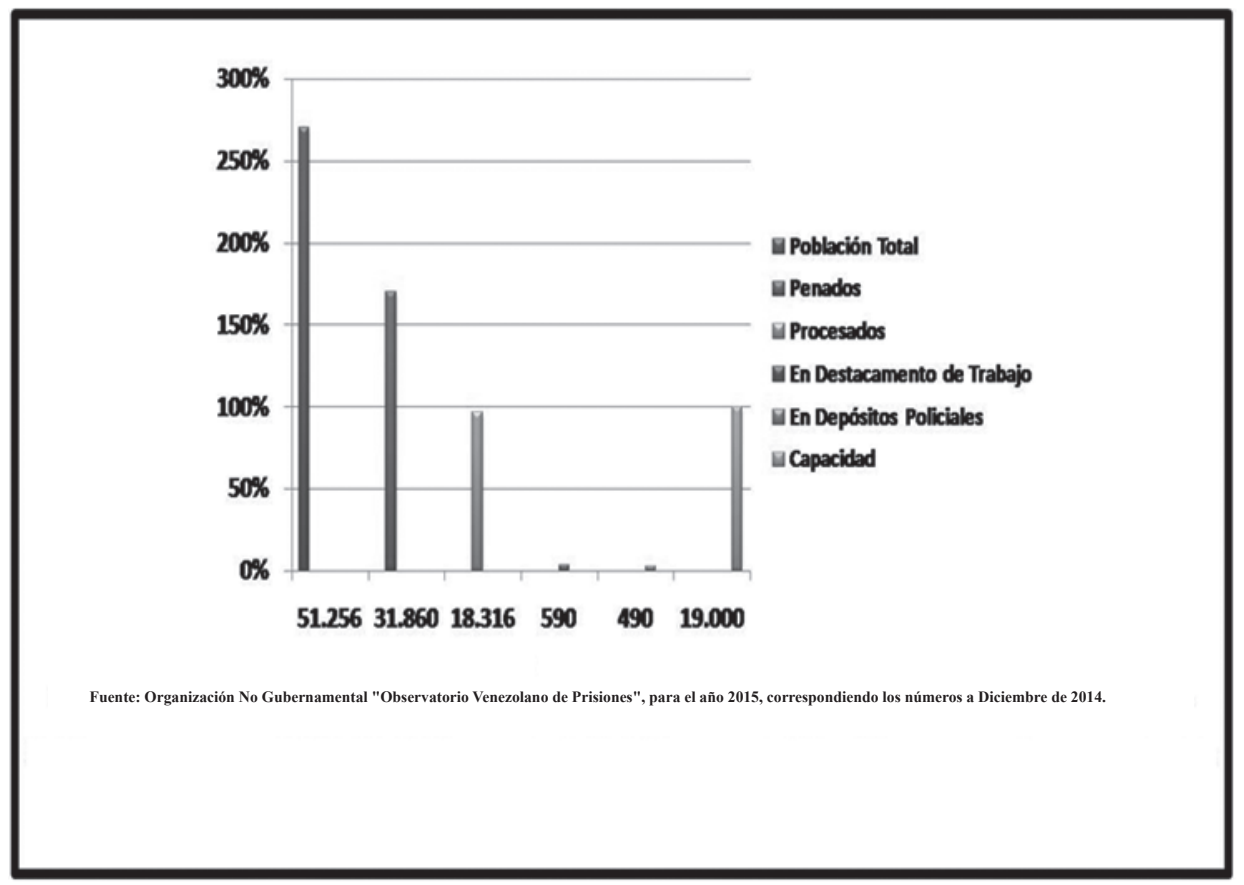

Fuente: Elaboración propia. 
Gráfico Nro. 3 "Discriminación de la población por sexo"



Fuente: Elaboración propia.

Como agregado, hay que desnudar la labor de los Jueces de Ejecución, quienes tienen encomendado vigilar el cumplimiento de las penas, además de inspeccionar los establecimientos de reclusión, de acuerdo al artículo 471 del Código Orgánico Procesal Penal, lo cual no se materializa en la práctica, al igual que la exigua participación de los Fiscales del Ministerio Público en fase de ejecución de sentencias, en resguardo de los derechos humanos de las cárceles según los artículos 16 y 39 de la Ley Orgánica del Ministerio Público ${ }^{29}$.

\footnotetext{
${ }^{29}$ El artículo 16 de Ley Orgánica del Ministerio Público contempla: "Son competencias del Ministerio Público: Garantizar el debido proceso, la celeridad y buena marcha de la administración de justicia, el respeto de los derechos y garantías constitucionales, así como de los tratados, convenios y acuerdos internacionales vigentes en la República, actuando de oficio o a instancia de parte". Asimismo, el artículo 39 ordinal séptimo establece: "Son deberes y atribuciones de los Fiscales o de las Fiscales del Ministerio Público de ejecución de la sentencia: 7) Vigilar e inspeccionar para que en los retenes policiales, en los locales carcelarios, en los lugares de reclusión de los comandos militares, en las colonias de trabajo, en las cárceles y penitenciarías, institutos de corrección para niños, niñas y adolescentes, y demás establecimientos de reclusión e internamiento, sean respetados los derechos humanos y constitucionales de los reclusos o reclusas, y de los niños, niñas o adolescentes...".
}

\section{DERECHO GLOBAL. ESTUDIOS SOBRE DERECHO Y JUSTICIA}




\section{Ilustración Nro. 1 "Imagen del Internado Judicial de Tocuyito, Valencia, estado Carabobo"}



Fuente:https://www.el-carabobeno.com/wp-content/uploads/2016/11/tocuyito-768x510.jpg

En tercer escalón, las actividades diarias redentoras de las penas no se cumplen a cabalidad, dado el alto número de privados de libertad que hace imposible su manejo en los recintos, optando los directores por mayor encierro y menos trabajo o estudio. Agregado a ello, las opciones laborales en las prisiones venezolanas no generan un aporte económico real para el trabajador, lo que no contribuye a la inserción social, a pesar del regimiento del Instituto Autónomo Caja de Trabajo Penitenciario, una institución que no ha logrado emplear ni en sus mejores momentos a más del $13 \%$ de los privados de libertad.

En el contorno educativo, el mayor problema que existe actualmente está directamente ligado a los actores: por un lado, la deserción de los profesores y facilitadores por los sueldos vigentes, y por el otro lado, la escasa matriculación de los privados de libertad. En esta visión, Román (2020b: 133) estipula como límites para la inserción educativa en contextos de encierro los siguientes aspectos: 
... la convivencia forzada, fractura familiar, restricciones afectivas, carencia alimentaria, deficiencia de los servicios médicos y odontológicos, inaccesibilidad a servicios de internet, escasez de libros en la biblioteca, la incertidumbre diaria y prisionización, riñas, motines, las pautas de la subcultura delincuente, agresividad, violencia interna y baja autoestima.

Por otra parte, las personas privadas de libertad se esfuerzan por tomar las medidas de higiene que les permitan salir en libertad sanos, frente al cúmulo de enfermedades que se han acrecentado en los últimos años en las organizaciones penitenciarias, especialmente, la tuberculosis. Ahora bien, una deuda grande del Estado Venezolano es "la no descentralización" de las prisiones, lo cual sería una salida a tantos problemas que aquejan las prisiones. Por un extremo, para que los estados y municipios asuman responsabilidades naturales, además que, habiendo 24 gobernaciones y 333 alcaldías, difícilmente todas puedan hacerlo mal.

\section{Conclusiones}

Acobijados en el paradigma constitucional de los Derechos Humanos y en los valores del Estado Democrático y Social de Derecho y de Justicia apostamos por la humanización de las organizaciones penitenciarias y el resguardo de los derechos de las personas privadas de libertad, con ánimo de procrear una íntegra conciencia social y subsecuente reinserción.

Desde el bucle educativo, frente a la "Universidad del Crimen", como se ha marginado a las cárceles por su realidad; también existe la "Universidad de la Estigmatización", conformada por los integrantes de la sociedad que ejercen la violencia simbólica y la educan, de generación en generación, con eufemismos cada vez más elaborados, para segregar e invisibilizar a sus pares.

Por supuesto, que todo ello deviene de la ineludible obligación de toda persona post penitenciaria de no reincidir y vivir bajo las máximas del respeto como columna vertebral de las relaciones interpersonales. Por ello, los sistemas penitenciarios de avanzada creen y apuestan por las segundas oportunidades, y

\section{DERECHO GLOBAL. ESTUDIOS SOBRE DERECHO Y JUSTICIA}


nosotros debemos comenzar a navegar esas aguas, para garantizar el Sistema Nacional de Protección de los Derechos Humanos que enarbola la Constitución. En definitiva:

PRIMERO: el servicio penitenciario venezolano ha estado signado a lo largo de su historia por los mismos problemas: edificaciones ruinosas, hacinamiento, carencia de recursos, ocio, drogas, violencia institucional e intracarcelaria, carencia de oportunidades laborales, en fin, vulneración a los derechos fundamentales.

SEGUNDO: los instrumentos internacionales, constitucionales y legales prescriben un acervo normativo desde el paradigma de los derechos humanos que debe motorizar una profunda reflexión sobre la realidad penitenciaria y generar políticas sociales y humanistas que realmente transformen el sistema.

TERCERO: a pie y renglón de lo anterior, la educación es el principio nuclear para la resocialización, como derecho humano de todo individuo, creadora de nueva conciencia, conjugando la educación formal con la educación en valores, más allá de los contenidos curriculares.

CUARTO: el Penitenciarismo Constitucional ha quedado en letra muerta, toda vez que las políticas ministeriales han sido insuficientes para cumplir con el mandato de la lex superior, debido a problemas presupuestarios, manejo de un porcentaje de prisiones por parte de PRANES, hacinamiento desbordado, mayores índices de criminalidad y retardo procesal injustificado.

QUINTO: el objeto de las organizaciones penitenciarias debe ser egresar una persona con nueva conciencia, transformada y emancipada a través de la educación y el trabajo, con competencias generales y específicas para un área determinada en el mercado laboral, en donde se le brinden nuevas oportunidades, contribuyendo al desarrollo productivo del país, abandonando la reincidencia. 
Este es el penitenciarismo constitucional de esta centuria: rehabilitación y reinserción de la mano de la educación. Esto no se ha cumplido. Pese a ello, creemos que solo el trabajo mancomunado de los actores sociales (Estado, Empresas, Universidad, Iglesia, Sociedad Civil, Medios de Comunicación, Familia y Privados de Libertad) podría provocar un verdadero cambio.

\section{RECOMENDACIONES}

Algunas recomendaciones han quedado al final de este trayecto, sea para quienes les competa la gestión pública penitenciaria, para los docentes, para otros investigadores o la sociedad en general.

PRIMERO: es posible que las Universidades que funcionen en las penitenciarías realicen programas conjuntos con el Ministerio respectivo para generar espacios de divulgación de los productos intelectuales en las cárceles y a la inversa, así como la visita de los estudiantes privados de libertad a las Bibliotecas Universitarias donde ellos estén matriculados, incidiendo positivamente en su proceso de aprendizaje e interacción social.

SEGUNDO: fortalecer los programas nacionales de formación de los funcionarios penitenciarios en la educación en y para los derechos humanos.

TERCERO: descentralizar los centros de reclusión.

CUARTO: crear mesas de trabajo con todos los actores sociales para articular las políticas de segunda oportunidad de las personas post penitenciarias.

QUINTO: educar desde la infancia a todas las personas para precaver el uso de estereotipos cargados de resentimiento en contra de las personas privadas de libertad, pulverizando la pena de banquillo con tanto importe para el país. 


\section{Bibliografía}

Áñez, M. (2015). El discurso penitenciario en Venezuela. Una reflexión teórica. Frónesis, Revista de Filosofía Jurídica, Social y Política, Volumen 22(1). pp. 19-39. Recuperado de: http://www.revencyt.ula. ve/storage/repo/ArchivoDocumento/frone/v22n1/art03.pdf

Bardin, L. (2002). El análisis de contenido. España: Ediciones Akal.

Bronfenbrenner,U.(1987).Laecologíadeldesarrollohumano, experimentos en entornos naturales y diseñados. España: Ediciones Paidós. Recuperado de: http://www.bibliopsi.org/docs/carreras/electivas/ ECFP/Orientacion-vocacional-Aisenson/bronfenbrenner $\% 20 \% 20$ la\%20ecologia\%20del\%20desarrollo\%20humano.\%20parte\%20I.pdf Código Orgánico Penitenciario. (2013). Venezuela: Asamblea Nacional. Gaceta oficial N ${ }^{\circ} 6.207$ de fecha 28 de diciembre de 2015.

Código de Enjuiciamiento. Criminal. (1961). Venezuela: Congreso de la República de Venezuela. Gaceta Oficial N 748 de fecha 03 de febrero de 1962.

Código Orgánico Procesal Penal. (1998). Venezuela: Congreso de la República de Venezuela. Gaceta Oficial № 37.022 de fecha 25 de agosto de 2000.

Código Orgánico Procesal Penal. (2012). Venezuela: Asamblea Nacional de la República Bolivariana de Venezuela. Gaceta Oficial Extraordinaria $\mathrm{N}^{\circ} 6.078$ de fecha 15 de junio de 2012.

Constitución de la República Bolivariana de Venezuela. (1999).

Venezuela: Asamblea Nacional Constituyente. Gaceta Oficial de la República Bolivariana de Venezuela $\mathrm{N}^{\circ} 36.860$.

Europa Press. (03/01/2020). "Venezuela inicia el año 2020 con la cifra récord de 388 presos políticos, según Foro Penal". Notimérica. Recuperado de https://www.notimerica.com/politica/noticia-venezuelavenezuela-inicia-ano-2020-cifra-record-388-presos-politicos-foropenal-20200103222350.html 
Goffman, E. 2001. Internados: ensayos sobre la situación social de los enfermos mentales. Argentina: Amorrortu.

Gómez, S. (12/07/2020). "Venezuela Tuberculosis y desnutrición, la pandemia de las cárceles venezolanas”. El Diario. Recuperado de https://eldiario.com/2020/07/12/tuberculosis-y-desnutricion-lapandemia-de-las-carceles-venezolanas/

Gómez Grillo, E. (1989). Ocio, drogas, violación y muerte. Una cárcel venezolana por dentro. Nueva sociedad (100), marzo-abril 1989. pp 144-151. Recuperado de https://nuso.org/media/articles/ downloads/1743_1.pdf

. (2000). "Penas, Penales y Penitencias", en Asdrúbal Baptista (ed.), Venezuela Siglo XX Visiones y Testimonios, Libro III (pp. 169-189). Venezuela: Fundación Empresas Polar. Recuperado de https://bibliofep.fundacionempresaspolar.org/publicaciones/libros/ venezuela-siglo-xx-visiones-y-testimonios/

. (2001). Cuando la Constitución entra a la cárcel. Anales de la Universidad Metropolitana, Volumen 1 (1), Nueva Serie. pp. 99-101. Recuperado de https://dialnet.unirioja.es/descarga/articulo/4005955. pdf

. (2002). "El Nuevo Penitenciarismo Constitucional", en Constitución de la República Bolivariana de Venezuela vista por sus redactores (pp. 74-76). Venezuela: Editorial Tecnocolor.

. (2009). Prosa de Prisa para Presos. Caracas: Fondo Editorial IPASME. Recuperado de https://fondoeditorialipasme.files. wordpress.com/2010/08/prosa-de-prisa-para-presos.pdf

Ley Orgánica del Ministerio Público. (2007). Venezuela: Asamblea Nacional. Gaceta Oficial $N^{\circ} 38.647$ de fecha 19 de marzo de 2007. http://www.derechos.org.ve/pw/wp-content/uploads/LeyOrg\%C3\%A1 nica-del-Ministerio-P\%C3\%BAblico.pdf

Leal, J. (2017). La autonomía del sujeto investigador y la metodología de la investigación. Valencia, Venezuela: Signos C.A. 
Ley de Régimen Penitenciario. (2000). Venezuela: Comisión Legislativa Nacional. Gaceta Oficial No36.975 de fecha 19 de junio de 2000.

Lugo, M. (2018). Resignificación de la Gerencia Universitaria en la Función Investigación: un constructo teórico a partir de la voz de sus actores. (Tesis Doctoral). Universidad Yacambú: Barquisimeto, Venezuela.

Melina, C. y Mikulic, I. (2004). Calidad de vida percibida: estudio de los factores de riesgo y protección en sujetos privados de libertad. XI Jornadas de Investigación. Facultad de Psicología - Universidad de Buenos Aires, Argentina. Recuperado de https://www.academica. org/00-029/254.

Morais, M. (1992). La Constitución Venezolana y la Ley del Régimen Penitenciario. Compatibilidades y contradicciones. Revista de la Facultad de Derecho, número 44, abril 1992. pp. 75-106. Universidad Católica Andrés Bello. Recuperado de http://biblioteca2.ucab.edu. ve/anexos/biblioteca/marc/texto/Revderecho44.pdf

. (2009). Situación actual de los Derechos Humanos en las cárceles de Venezuela. Caracas, Venezuela: Instituto Latinoamericano de Investigaciones Sociales (ILDIS) y Observatorio Venezolano de Prisiones (OVP). Recuperado de https://library.fes.de/pdf-files/ bueros/caracas/08790.pdf

. (2010). Hacia una Agenda Alternativa para la Exigibilidad de los Derechos Humanos de la Población Reclusa. Caracas, Venezuela. Instituto Latinoamericano de Investigaciones Sociales (ILDIS) y Observatorio Venezolano de Prisiones (OVP). Recuperado de http:// library.fes.de/pdf-files//bueros/caracas/08808.pdf

ONU. (1948). Declaración Universal de los Derechos Humanos. Recuperado de https://www.un.org/es/documents/udhr/UDHR_booklet_SP_web.pdf - (2015). Reglas Mínimas de las Naciones Unidas para el Tratamiento de los Reclusos (Reglas Nelson Mandela). Recuperado de https://undocs.org/es/A/RES/70/175 
Observatorio Venezolano de Prisiones -OVP-. (2015). Informe sobre la situación de privados de libertad en Venezuela con motivo de la revisión del tercer informe periódico de la República Bolivariana de Venezuela ante el Comité de Derechos Económicos, Sociales y Culturales de la ONU. pp. 1-6. Caracas, Venezuela. Recuperado de https://tbinternet.ohchr.org/Treaties/CESCR/Shared\%20Documents/ VEN/INT_CESCR_CSS_VEN_20352_S.pdf

Payares, E. y Boueiri, S. (2011). "La reinserción social como política del estado venezolano: un análisis teórico-empírico en torno a las unidades de tratamiento, supervisión y orientación", en Daniela Zaikoski Biscay y Manuela G. González (comps.), Actas del XII Congreso Nacional y II Latinoamericano de Sociología Jurídica: problemas sociales de Latinoamérica, desafíos al campo jurídico. Argentina: Universidad Nacional de La Pampa y EdUNLPam.

Pizano, A. (2013). El impacto del nuevo paradigma constitucional de los derechos humanos en la readaptación social del preso. (Tesis de Maestría). Universidad Michoacana de San Nicolás de Hidalgo: México. Recuperado de http://bibliotecavirtual.dgb.umich.mx:8083/ xmlui/bitstream/handle/DGB_UMICH/514/FDCS-M-2013-0164. pdf? sequence $=1$

Presidencia de la República Bolivariana de Venezuela. Decreto $N^{\circ} 8.266$ por el cual se crea el Ministerio del Poder Popular para el Servicio Penitenciario. Gaceta Oficial No 39.721 de fecha 26 de julio de 2011. Programa Venezolano de Educación-Acción en Derechos Humanos -PROVEA-. (2014). Situación de los Derechos Humanos en Venezuela. Informe Anual Enero-Diciembre 2013. Derechos de las personas privadas de libertad. pp. 415-432. Caracas, Venezuela. Recuperado de https://www.derechos.org.ve/web/wp-content/ uploads/20Privados-de-libertad.pdf

. (s/f). Nuestra historia. Recuperado de https://www.derechos. org.ve/provea 
Román, V. (2020a). Insumos gerenciales emergentes para la disminución de los efectos de la prisionización. Revista Científica Gerens (6), enero-junio 2020. pp. 61-70. Recuperado de http://www.unellez.edu. ve/revistas/index.php/rgerens/article/download/1091/983 . (2020b). La Educación Universitaria en las Organizaciones Penitenciarias. Memoralia (19), enero-junio 2020. pp. 128-138. Recuperado de http://www.unellez.edu.ve/revistas/index.php/ rmemoralia/article/view/1010

Useche, J. (2001). La Justicia en el Texto Constitucional Venezolano. Anuario de Derecho Comparado, Número 24. Instituto de Derecho Comparado de la Universidad de Carabobo. Recuperado de http:// servicio.bc.uc.edu.ve/derecho/revista/idc24/24-8.pdf 